\title{
The emergence of parvoviruses of carnivores
}

\author{
Karin Hoelzer, Colin R. PARrish* \\ Baker Institute for Animal Health, Department of Microbiology and Immunology, \\ Cornell University, College of Veterinary Medicine, Hungerford Hill Road, Ithaca, NY 14853, USA
}

(Received 11 November 2009; accepted 10 February 2010)

\begin{abstract}
The emergence of canine parvovirus (CPV) represents a well-documented example highlighting the emergence of a new virus through cross-species transmission. CPV emerged in the mid-1970s as a new pathogen of dogs and has since become endemic in the global dog population. Despite widespread vaccination, CPV has remained a widespread disease of dogs, and new genetic and antigenic variants have arisen and sometimes reached high frequency in certain geographic regions or throughout the world. Here we review our understanding of this emergence event and contrast it to what is known about the emergence of a disease in mink caused by mink enteritis virus (MEV). In addition, we summarize the evolution of CPV over the past 30 years in the global dog population, and describe the epidemiology of contemporary parvovirus infections of dogs and cats. CPV represents a valuable model for understanding disease emergence through cross-species transmission, while MEV provides an interesting comparison.
\end{abstract}

canine parvovirus / mink enteritis virus / disease emergence / viral evolution

\section{Table of contents}

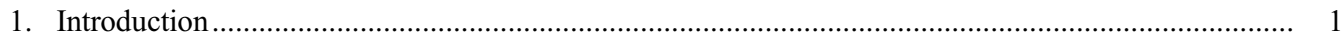

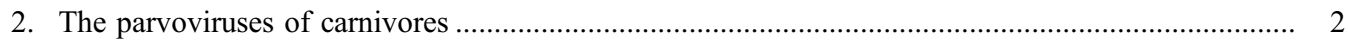

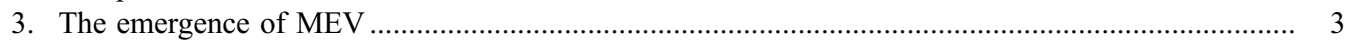

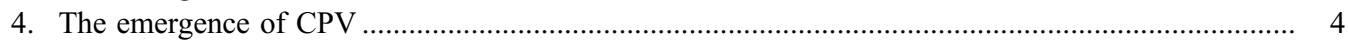

5. Continuing evolution and spread of $\mathrm{CPV}$ in the global dog population - the roles of capsid variants ........ 7

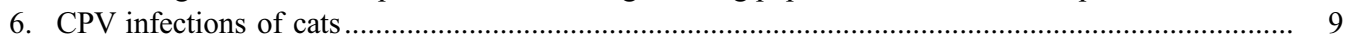

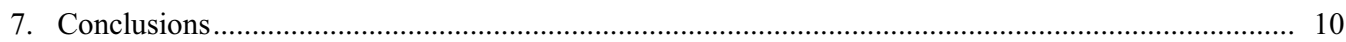

\section{INTRODUCTION}

Members of the parvovirus genus (i.e. autonomous parvoviruses, subfamily Parvovirinae) infect a wide variety of mammalian hosts including pigs, several members of the order Carnivora (henceforth referred to as "carnivores") and various rodents, and are characterized by more or less strict host specificity $[13,42]$. Carnivores are infected by three closely

\footnotetext{
* Corresponding author: crp3@cornell.edu
}

related autonomous parvoviruses which we will refer to as "carnivore parvoviruses", canine parvovirus (CPV), feline panleukopenia virus (FPV) and mink enteritis virus (MEV). Dogs and mink are also hosts for other distantly related viruses in the same subfamily, including the minute virus of canines (also known as CPV type-1 or canine minute virus) and Aleutian mink disease virus (AMDV) which belong to the Bocavirus and Amdovirus genera, respectively. There appear to be no immunological, epidemiological or pathological interactions

This is an Open Access article distributed under the terms of the Creative Commons Attribution-Noncommercial License (http://creativecommons.org/licenses/by-nc/3.0/), which permits unrestricted use, distribution, and reproduction in any noncommercial medium, provided the original work is properly cited. 
between CPV-1 or AMDV and CPV, FPV or MEV respectively in their various hosts.

Parvoviruses are non-enveloped viruses with a capsid of about $25 \mathrm{~nm}$ in diameter, that package a single-stranded DNA genome of approximately 5000 bases. The genomes are simple and contain two large open reading frames (ORF) as well some smaller or overlapping genes, mostly generated by alternative splicing. In the conventional orientation, the right-hand ORF encodes the capsid proteins and the lefthand ORF encode the non-structural proteins (reviewed for example in [14]). Parvovirus capsids are highly antigenic and play major roles in determining viral host ranges and tissue tropisms (reviewed for example in [31]). The non-structural proteins are multi-functional and required for viral gene expression and genome replication. Parvoviruses replicate using various components of the host cell DNA replication complex and, since they cannot induce mitosis, only replicate in actively dividing cells [47]. Several aspects of this replication scheme including the likely lack of involvement or absence of some subunits of the host cell DNA polymerase complex, the rapid replication of the genome, and the single-stranded nature of the parvovirus genome - lead to a lower fidelity of parvovirus replication compared to that observed during cellular DNA replication (reviewed in [25]). While parvoviruses of rodents and AMDV can establish long-lasting or persistent infections, carnivore parvoviruses are usually cleared within 10 days of infection, after which little residual viral DNA remains $[1,54,59]$. The immune response that protects animals against parvovirus infection is predominantly humoral, and antibodies efficiently neutralize most parvoviruses. The important role of antibodies in protecting animals from infection is emphasized by the effectiveness of maternal immunity, which is antibody mediated, and which confers efficient protection against these parvoviruses. Infections occur predominantly in young animals after maternal antibodies have declined to low levels, generally between 2 and 4 months of age depending on the maternal antibody titer and level of transfer. Cell mediated immunity clearly plays an important role in recovery from disease.

\section{THE PARVOVIRUSES OF CARNIVORES}

Carnivore parvoviruses are endemic in most domestic and feral carnivore populations and they infect a variety of host species (see for example $[19,21,28,62,64,67,73,77])$. The related group of "FPV-like" viruses, which includes FPV, viruses from raccoons (termed RPV) and arctic foxes (termed blue fox parvovirus (BFPV)), has been widespread for many decades. "FPV-like" viruses infect various hosts including domestic and wild cats, lions, tigers, leopards, cougars, lynx, civets, leopard cats, arctic foxes and raccoons $[7,8,19,32$, $64,65,74]$. These viruses are all very similar, appear to be transmitted readily among these hosts, and form a monophyletic clade in phylogenetic analyses of the viral sequences [56, 66]. However, FPV-like viruses do not spread among dogs, which are infected only in thymus and bone marrow and therefore do not appear to allow onward transmission [68].

As parvoviruses only infect actively dividing host cells, the clinical manifestations of disease are strongly dependent on the age of the host, and symptoms are similar in wild and domestic animals [54]. In animals older than about 4 weeks, the virus mainly replicates in the tissues containing proliferating cells, including the bone marrow, lymph nodes, the spleen in some cases, and the progenitor cells in the crypts of Lieberkühn in the intestine. Cytolysis of bone marrow and other lymphoid cells leads to lymphopenia or leukopenia, while loss of intestinal epithelial cells can lead to hemorrhagic enteritis, the most pronounced clinical symptoms associated with parvovirus infections of carnivores. Lymphoid depletion can involve loss of all myeloid progenitor cells, decreasing the number of circulating thrombocytes, erythrocytes, granulocytes and mast cells. However, viral strain, individual host and host-species differences result in preferential tissue tropisms and differential clinical symptoms, so that the manifestation of clinical disease can vary from severe to subclinical. If animals survive the acute infection, complete recovery normally occurs.

Where maternal immunity is not present, infection of neonatal animals and fetuses may 
occur. In those animals additional tissues can be infected, and virus replication is seen in the myocardium and/or cerebellum, leading to myocarditis in puppies, and cerebella hypoplasia in kittens. In rare cases, infections in utero can lead to abortion or generalized viral replication in numerous fetal organs [74]. Intriguingly, no signs of diarrhea are observed in neonatal animals, likely due to the lower rate of replication of the intestinal epithelium early in life, but infections of fetuses and neonates are generally fatal or lead to debilitating permanent damage.

Parvoviruses are extremely stable in the environment and indirect transmission likely plays an important role in the transmission and maintenance of viruses in a population, particularly in wild carnivore populations which may be characterized by low contact rates between animals. Transmission between domestic and wild carnivores also probably occurs readily, and while direct transmission through close contact or predation on smaller carnivores has been proposed, the viruses are probably readily transmitted across long distances by fomites. Carnivore parvoviruses can spread rapidly, and in naïve populations there can be a high associated mortality that can lead to considerable decreases in population size (see [5] for a review of this topic). In populations in which the viruses are endemic, new cases occur mainly in young animals that become infected after maternal antibodies wane, and for seasonal breeders the infection dynamics can depend heavily on the replenishment of young susceptible animals, frequently leading to cyclical infection dynamics [5].

Vaccination is the main method of controlling disease in domestic animals and in captive populations of wild carnivores. FPV vaccines of various types have been on the market since the 1950s, and vaccines for MEV and CPV were developed soon after these diseases emerged, with the first CPV vaccine available in 1979. These vaccines are also frequently used in captive wild carnivores where they appear to be safe and to confer protective immunity. However, those vaccines have not been explicitly tested in or licensed for use in the wildlife species, and questions remain regarding dosage, the most appropriate type of vaccines to use in which wildlife species, the frequency of re-vaccination, and the level of protection conferred.

\section{THE EMERGENCE OF MEV}

MEV was first described as a disease of mink in 1947 when it caused devastating disease in farmed mink [63]. Initially, the disease was reported in Ontario, Canada, but was reported world-wide within a few years, and it is currently endemic wherever mink are farmed $[63,66]$. MEV likely also infects wild mink, although the impact on their health is not known. MEV can cause acute hemorrhagic enteritis in mink, in particular in younger animals, and is frequently associated with leukopenia. The virus is highly transmissible on and between mink farms, and in extreme cases can cause mortalities of 20 to $80 \%[10,75]$. When MEV emerged in mink, the clinical and pathological similarities to FPV infections were soon recognized, and antigenic similarities between the two viruses were first shown by Wills in 1952 [75]. He documented that FPV confers cross-protection against MEV infection of mink and that the reciprocal is true for MEV, which protects against FPV infection of cats $[10,76]$. Inactivated FPV tissue-derived vaccines were used successfully in the field to protect mink against MEV [76]. FPV and MEV do not appear to differ significantly in host range and both viruses can replicate efficiently in cats and mink. However, the viruses may differ in virulence and tissue tropism, and each virus appears less pathogenic in the heterologous host. In fact, in mink histological differences between lesions caused by MEV and FPV were reported as early as 1959 [43, 51]. Intriguingly, FPV and MEV capsid protein genes are phylogenetically indistinguishable and form a single clade within parvovirus phylogenies $[64,70]$. The reasons for the sudden emergence of MEV have remained unclear and the subject has received only limited attention, mostly since CPV emerged in the 1970s. Changes in viral virulence leading to increased recognition of the disease have been suggested as drivers 
of MEV emergence or at least recognition, and the fact that FPV readily infects but does not cause significant disease in related Mustelidae such as otters, skunks and ferrets supports this notion, but further research is needed to test this hypothesis [4, 66]. It is possible that MEV adapted to mink during the initial period of rapid viral spread. The high population density, especially the increased density of susceptible young animals resulting from the single short breeding season, and perhaps changes in husbandry practices on commercial mink farms, may have facilitated MEV emergence or recognition. MEV may therefore represent a mink-adapted variant of FPV, but clear genetic signatures of this adaptation have not been identified.

Similarly scarce is data on the $>60$ years of MEV evolution in mink, and potentially in other carnivores. MEV-like viruses are endemic wherever mink are farmed and outbreaks have been reported in Canada, the USA, Denmark, Sweden, Finland, France, the Netherlands, Poland and the UK $[9,10]$. Asymptomatic carriers have been implicated in the dispersion of MEV across the globe, but clear epidemiological evidence for this mode of spread is limited. During the early outbreaks in the 1950s, MEV was frequently found to repeatedly affect the same farms, indicating likely year-to-year persistence in the environment, or management practices that favored reintroduction of the virus. MEV can reach high prevalences on infected farms, and disease tends to be particularly high in the later summer, with the seasonal replenishment of naïve hosts likely contributing to this phenomenon.

Three antigenic variants of MEV have been recognized, which differ by only small numbers of amino acid sequence changes in the capsid protein, and cross-immunity protects mink from infection with both homologous and heterologous MEV strains [49]. The relative abundance, geographic distribution and clinical importance of these antigenic types, however, are unclear, and those and many other questions concerning the emergence, epidemiology and evolution of MEV have so far remained unanswered.

\section{THE EMERGENCE OF CPV}

In early 1978, a new parvovirus of dogs was identified, referred to as CPV type-2 (CPV-2) to distinguish it from the distantly related minute virus of canines. CPV-2 caused FPV-like hemorrhagic enteritis with associated leukopenia in dogs [2, 3]. The disease was characterized by a high associated mortality and within a few months CPV was detected around the world [55]. Phylogenetic studies and analysis of historical samples show that CPV emerged in the early to mid-1970s, only a few years prior to its first recognition [26, 64, 70]. Based on serological testing, dogs in Europe or Eurasia were infected before 1978 (between 1974 and 1976), after which the virus became distributed in dogs world-wide during the first half of 1978 $[55,69]$. The specific ancestral strain of virus that gave rise to CPV has not been identified, but CPV clearly derived from either FPV or one of the closely related viruses of wild carnivores. A phylogenetic analysis of several FPVlike viruses collected during the 1960s, 1970s, and 1980s revealed a virus strain from a farmed arctic fox in Finland as most closely related to CPV [70]. A partial parvovirus DNA sequence from a German red fox also appeared to be intermediate between FPV and CPV, at least for the genomic region covered. A role of wildlife reservoirs in the emergence of $\mathrm{CPV}$ has thus been proposed, but conclusive evidence is not yet available $[66,73]$.

The original 1978 strain of virus was designated as CPV-2, and during 1979 a variant virus emerged, referred to as CPV-2a. That virus replaced the CPV-2 strain world-wide during 1979 and 1980, and it is the descendents of CPV-2a that continue to circulate around the world [26, 53] (Fig. 1). The CPV-2 and CPV-2a strains differ in a number of properties, including antigenic structure when analyzed with monoclonal antibodies, the affinity of binding to the feline transferrin receptor (TfR), and the ability to replicate in cats [68]. Although CPV-2 was unable to replicate in cats, the CPV-2a strains isolated in the 1980s efficiently infected cats and an estimated $10-20 \%$ of feline cases of parvovirus disease 


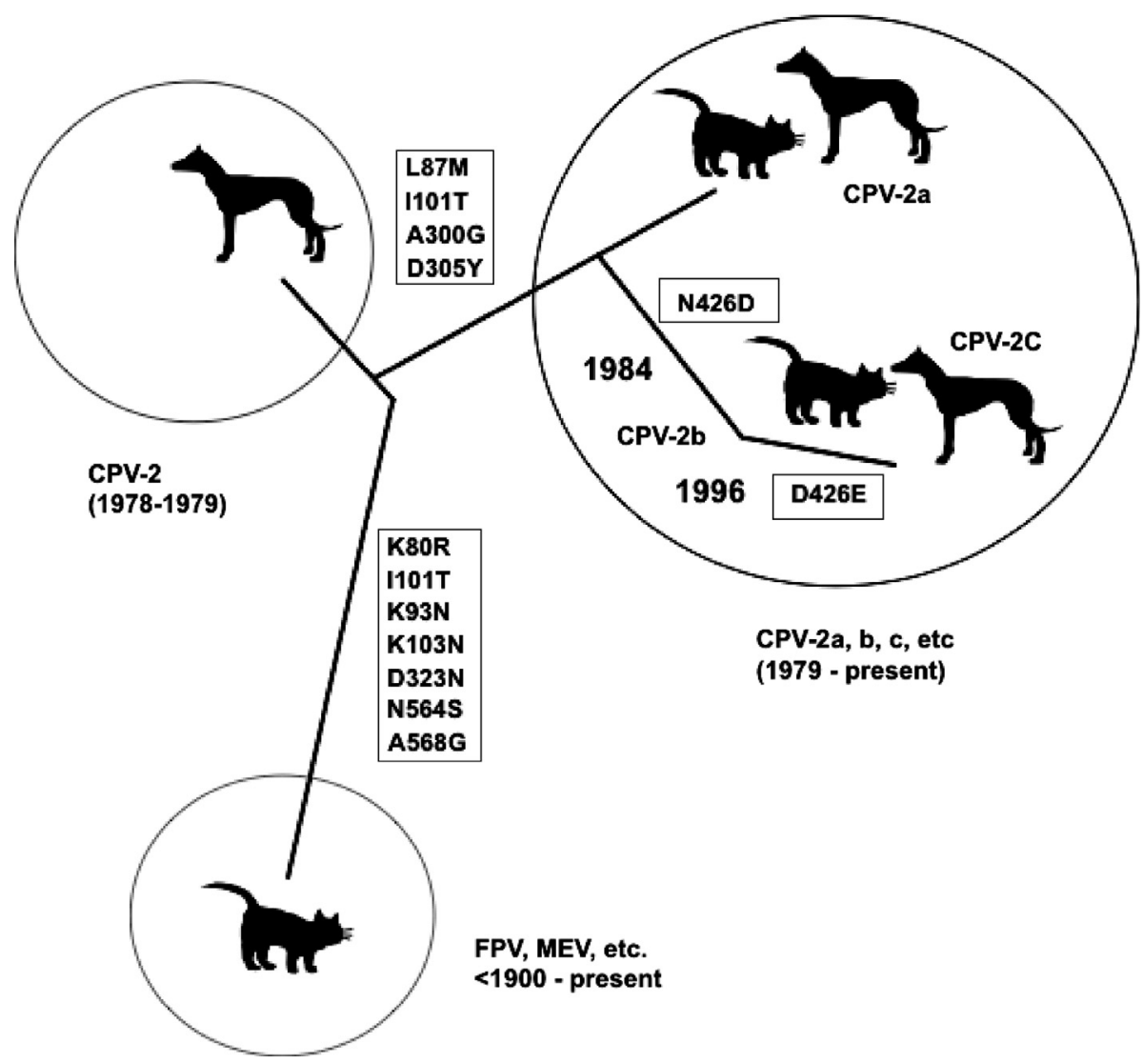

Figure 1. Genetic relationship and host ranges of FPV, CPV and related parvoviruses. The host range, year of emergence and genetic relationship are indicated. Where these have been identified, host-range and strain-defining mutations are indicated.

in Germany, Japan and the USA during that time were caused by CPV (although the sample sizes analyzed were small) [70-72].

The canine and feline host ranges of CPV and FPV appear to be controlled primarily by residues in the viral capsid. The ability of CPV to bind the canine TfR and infect canine cells is largely controlled by mutations of VP2 residues 93 (Lys to Asn) and 323 (Asp to Asn) in the viral capsid, which together determine the canine host range of CPV [29, 30, 55] (Fig. 1). The mutations in CPV-2 which affect the ability to infect and replicate in cats have been less clearly defined, but at least two regions in the capsid protein gene, and in particular substitutions of VP2 residues 87, 300 and 305 appear to be involved [55]. Interestingly, these mutations are not the same residues that were changed during the emergence of CPV-2, although they are located in close spatial proximity in the viral capsid, indicating that they may have compensatory functions.

Phylogenetic analysis of the carnivore parvoviruses show that they fall into three distinct clades, with the longest internal branch separating the FPV-like viruses from the viruses isolated from dogs (Fig. 2). All currently known CPV-2- and CPV-2a-derived viruses are monophyletic, indicating that a single cross-species transmission event gave rise to all currently 


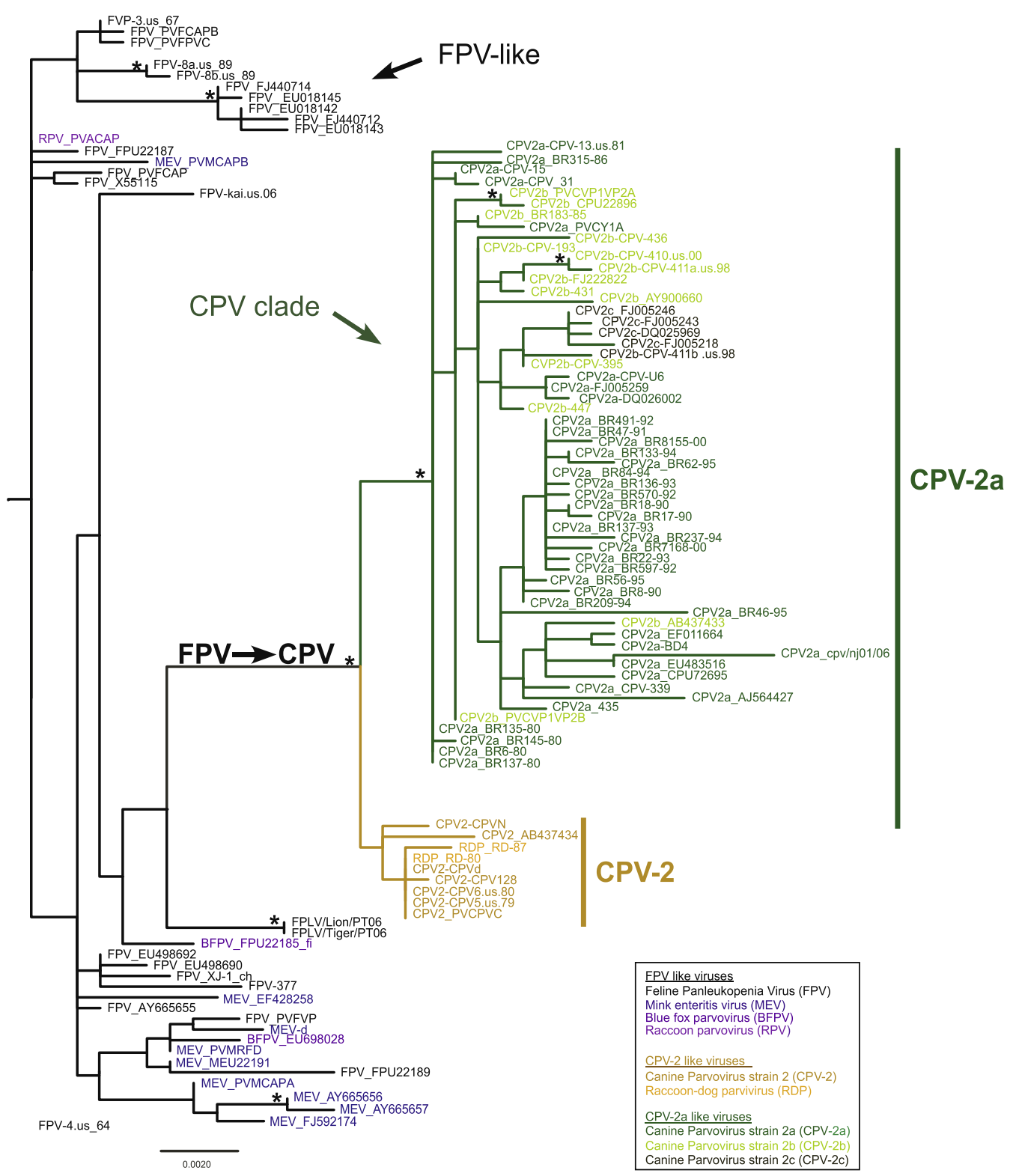

Figure 2. Phylogenetic relationship between the carnivore parvoviruses, based on the capsid protein gene VP2. Phylogenetic tree was constructed using PAUP* version 4.1 with the best model of nucleotide substitution determined using modeltest. Viruses are as follows: FPV: feline panleukopenia virus; BFPV: blue fox parvovirus; RPV: raccoon parvovirus; RDP: raccoon dog parvovirus; CPV: canine parvovirus; * nodes with bootstrap supports $>75 \%$. (For a color version of this figure, please consult www.vetres.org.)

known CPV strains [26, 64]. The CPV isolates are divided into two clades, with one clade containing the CPV-2 isolates, and as second, clearly distinguished clade, containing all other CPV-like viruses which are derived from a single CPV-2a ancestor (Fig. 2). Comparing the 
Table I. The emergence of specific mutations in the genome of CPV that became widespread during the evolution of the virus in dogs.

\begin{tabular}{|c|c|c|c|}
\hline $\begin{array}{l}\text { Mutation(s) } \\
\text { that have } \\
\text { become } \\
\text { widespread }\end{array}$ & $\begin{array}{l}\text { Mutant } \\
\text { virus name } \\
\text { (if any) }\end{array}$ & $\begin{array}{l}\text { Year of first } \\
\text { recognition } \\
\text { (approximate in } \\
\text { some cases) }\end{array}$ & $\begin{array}{l}\text { Relative } \\
\text { prevalence }\end{array}$ \\
\hline $\begin{array}{l}\text { VP2 residues } \\
80 \text { Arg to Lys } \\
93 \text { Lys to Asn } \\
103 \text { Val to Ala } \\
323 \text { Asp to Asn } \\
564 \text { Asn to Ser } \\
568 \text { Ala to Gly }\end{array}$ & FPV to CPV & & $\begin{array}{l}\text { Associated with the } \\
\text { host range switch } \\
\text { from cats to dogs. } \\
\text { Result in altered binding } \\
\text { to the canine transferrin } \\
\text { receptor. }\end{array}$ \\
\hline $\begin{array}{l}\text { VP2 residues } \\
87 \text { Met to Leu } \\
101 \text { Ile to Thr } \\
300 \text { Ala to Gly } \\
305 \text { Asp to Tyr }\end{array}$ & CPV-2a & 1979 & $100 \%$ by $\sim 1980$ \\
\hline VP2 residue 426 Asn to Asp & CPV-2b & 1984 & $30-80 \%$ between 1984 and 2005 \\
\hline VP2 residue 297 Ser to Ala & & 1990 & Increasing to $>90 \%$ by 2000 \\
\hline VP2 residue 426 Asp to Glu & $\mathrm{CPV}-2 \mathrm{c}$ & 2001 & $\begin{array}{c}\text { Increasing after } 2001 \text {, becoming } \\
\text { globally distributed; no estimate } \\
\text { available }\end{array}$ \\
\hline VP2 residue 440, Thr to Ala & & $\sim 2005$ & $\begin{array}{c}\text { Found in several countries } \\
\text { around world, no estimate } \\
\text { available }\end{array}$ \\
\hline
\end{tabular}

entire genomes of the viruses shows that FPV sequences are distinguished from $\mathrm{CPV}$ sequences by a total of 16 substitutions, of which 11 are located in the capsid protein genes, emphasizing the important role of the capsid in this emergence event [26]. Seven substitutions distinguish the genomes of CPV-2 and CPV-2a, of which 5 are located in the capsid protein gene [26].

At a population level, CPV is evolving significantly faster than FPV, with mean estimates equalling roughly $2 \times 10^{-4}$ and $8 \times 10^{-5}$ substitutions/site/year respectively, and the capsid protein gene region of the viral genome evolved more rapidly than the region encoding the nonstructural proteins [26]. Notably, the capsid protein gene substitution rate estimate associated with the emergence of CPV is within the ranges of the rates observed for rapidly evolving RNA viruses [64].

\section{CONTINUING EVOLUTION AND SPREAD OF CPV IN THE GLOBAL DOG POPULATION - THE ROLES OF CAPSID VARIANTS}

CPV has undergone considerable further evolution during the $>30$ years since it emerged (Figs. 1 and 2, Tab. I), but the dynamics of the spread and variation of the virus may have changed during that period. While the emergence of CPV-2, immediately after 1978, was characterized by global viral spread, the continuing evolution the CPV-2a on a population level has resulted in it become increasingly geographically subdivided, and viruses now 
appear to be circulating predominantly locally [26]. In fact, separate Taiwanese-Japanese, Vietnamese and Indian CPV populations have been described, and the gene flow between the different populations appears limited, indicating strongly geographically separated populations in these regions [11, 18, 23].

All CPV-2 isolates are essentially identical in nucleotide sequence, while viruses within the CPV-2a clade have become much more diverse, and can now be further subdivided by the mutations they harbour. However, these CPV-2a derived viruses form a monophyletic clade in the parvovirus phylogeny and likely have similar host ranges. Some of the point mutations that have arisen and reached high frequency in the CPV population alter the antigenic properties of the capsid. The group of CPV-2a mutations results in the change of one epitope compared to CPV-2, while a substitution of VP2 residue 426 from Asn to Asp altered a second epitope and defined the so-called CPV-2b strain [52] (Tab. I). Around the year 2000, another substitution of the same codon for residue 426 arose, changing the Asp426 to Glu, giving another antigenic variant referred to as CPV-2c. CPV-2b (426Asp) was detected world-wide soon after it first emerged in 1984, while since 2000 the CPV-2c strain (426Glu) has also been detected in many regions of the world including several European countries, Vietnam, North and South America $[15,27,36,58]$. The currently available data does not allow a complete analysis of the epidemiology and evolution of the CPV-2c variant, but a recent phylogenetic analysis of the capsid protein genes indicates that there is a European lineage containing the 426Glu, and separate genotypes with that change in North America and in Asia [17]. The original CPV-2a (426Asn) and CPV-2b co-circulated in many parts of the world after CPV-2b emerged around 1984, and the relative frequencies of the two strains appeared to vary by geographic region. For example, in Brazil CPV-2a and $-2 b$ co-circulated, at least after 1986, with CPV-2b the more prevalent variant between 1995 and $2001[12,57]$. In contrast, CPV-2a was seemingly the more dominant variant in Italy for several years in the 1990s, then CPV-2a and
CPV-2b reached similar frequencies in 1999/ 2000 [40]. In North America CPV-2b appears to have been the predominant subtype circulating for many years, while CPV-2c has become common since about 2007 [27, 36]. The reasons for the continuing co-circulation of the different strains or for the variation in subtype prevalence in different parts of the world are not understood [17]. Despite their antigenic differences, strong cross-immunity between CPV$2 \mathrm{a}$ and $\mathrm{CPV}-2 \mathrm{~b}$ protects recovered animals against infection by the heterologous strain, and there is clearly cross protection between the various strains and CPV-2c [38]. The fact that CPV-2c is characterized by an alternate mutation at VP2 residue 426 points to a special role of this residue in infection or immune evasion, and that codon is shown to be under positive selection in the viral genome. However, apart from the antigenic differences seen by monoclonal antibody analysis, other specific biological roles of the Asn, Asp, or Glu variants at this residue have not yet been defined [26].

A mutation altering VP2 residue 297 was first observed in viruses collected around 1990, and has since reached high frequency in the global CPV population [26]. This residue was found in a Brazilian study to be under strong positive selection [57]. It is unclear what functions VP2 residue 297 might be altering, as no antigenic variation was detected in viruses bearing this mutation, but it is located close to VP2 residues (such as 299 and 300) that control TfR binding, suggesting it may affect that function. It may also affect capsid stability as changing residue 297 in FPV or CPV-2 altered susceptibility of the viral capsid to proteolytic cleavage, although that effect was not observed if the mutation was created in the CPV-2a background [46].

Residue 300 is exposed on the surface of the capsid, is highly variable, alters the antigenic structure of the capsid, affects the binding to the TfR, and may be involved in controlling the feline host range of the viruses. This residue may be of particular importance during infections of cats, as viruses from CPV-infected cats frequently show additional mutations at this position [45]. Substitution of either VP2 residues 299 and 300 with negatively charged 
amino acids alters the interaction of the virus with the canine and feline TfR $[30,48]$. Those may also alter capsid stability since the mutation of this residue in the CPV-2 background changed the susceptibility of the viral capsid to proteolytic cleavage [46]. Mutations that changed residue 300 were responsible for the antigenic variation detected in MEV strains [49]. However, the true biological significance of changes of that residue remains obscure, and a role for antibody selection is plausible. Antibody neutralization of parvovirus capsids and any immune evasion it evokes in the virus are incompletely understood. Large parts of the capsid surface can be efficiently recognized by antibodies, and the overlaid footprints of several anti-CPV antibodies spanned large portions of the viral capsid, with the same residues being recognized by several neutralizing antibodies [22]. As many neutralizing antibodies show overlap with the TfR binding site, blockage of viral entry through hindrance of receptor binding may be a common method of $\mathrm{CPV}$ neutralization.

\section{CPV INFECTIONS OF CATS}

The role of CPV in causing infections or disease of cats has not been systematically analyzed. CPV has been isolated from a variety of domestic cats, as well as other more-or-less related carnivores, including raccoons, Asiatic raccoon dogs, cheetahs, mountain lions, leopard cats and a red panda [32, 33, 37, 60, 61, 65]. The disease caused by CPV in cats generally appears to be much milder than that seen in dogs infected with that virus, or that caused by FPV in cats. CPV has also been isolated from the feces of clinically healthy domestic and wild felines [41], suggesting that the virus was either shed long after infection, or that it causes very mild or subclinical disease. Experimental infections of specific pathogen free (SPF) cats with CPV lead to mild or subclinical disease [20,44]. However, CPV infections of SPF dogs also tend to induce mild or no clinical symptoms. Moreover, the experimental CPV infections of normal cats have resulted in clinical FPV-like symptoms in some cases, indi- cating a role for secondary infections or other underlying stressors in increasing the severity of CPV or FPV diseases (reviewed in [34]).

Some CPV-2a-derived isolates from cats and raccoons have had unique substitutions of VP2 residue 300, in particular Gly to Asp changes $[33,37,60]$, which would alter their antigenic properties, and also likely affect their receptor binding properties [30, 39]. Similar mutants of CPV made the viruses unable to bind efficiently to the canine TfR or infect dog cells $[39,50]$, although an example of one virus with 300Asp has been reported from a dog in Korea [35]. These mutations therefore are likely adaptations to the feline host, indicating that CPV evolution is otherwise maintained by adaptation to dogs. In fact, in a recent study where naïve kittens were challenged with a recent (2007) CPV-2b strain failed to result in detectable viral replication, while viral replication was more readily detected after challenge with an older CPV-2a isolate [24]. One earlier study including samples from the USA, Europe and Japan reported the detection of $\mathrm{CPV}$ in naturally infected cats at an estimate frequency of $10-20 \%$, indicating that cats were a natural host for CPV at that time, but the number of samples tested was small and little information was given about the sampling scheme and inclusion criteria [70]. Ikeda et al. reported the detection of CPV at high frequency in samples collected from domestic and wild cats in Japan and Vietnam, but several of these isolates contained substitutions of VP2 residue 300, only 19 isolates were examined, and the samples were not necessarily representative of the viruses in the population [33]. Given the continuing evolution and population subdivision in the CPV population, CPV strains in different parts of the world may differ in their infectivity to cats, but no systematic analysis is available to address this question. Most diagnostic tests do not discriminate between CPV and FPV infections, only clinically affected animals are tested in most cases, and large-scale epidemiological studies of CPV in cats have not been performed, so the true prevalence and significance of CPV in cats remains unknown.

Our knowledge of the evolutionary dynamics governing CPV infections of cats is also 
limited. Battilani et al. analyzed sequence diversity in the capsid protein gene of CPV sequences isolated from a single infected cat, which revealed a very heterogeneous viral population [6], including 10 distinct sequences among 14 cloned sequences examined. Those included two antigenically distinct $\mathrm{CPV}$ variants (CPV-2a and CPV-2c), suggesting that some of the variation was likely due to co-infection rather than de-novo arising mutations. Multiple cases of co-infection of dogs with CPV field strains and vaccine virus have also been reported recently [16], and similar events likely lead to mixed infections during parvovirus infections of cats. Moreover, we detected very homogenous viral populations but evidence of co-infection in some animals when we analyzed the intrahost population structures of natural infections by FPV in cats and CPV in dogs, indicating that co-infection might have been the source of variability of these viruses in vivo [24].

\section{CONCLUSIONS}

Many aspects of the emergence and subsequent spread of carnivore parvoviruses are now becoming clear, but a number of questions remain unanswered. The critical role of the viral capsid protein gene in the evolution of CPV and the importance of mutations changing multiple functions including host range, receptor binding and antigenicity, and likely other aspects of the viral life cycle and pathogenesis are now clear. The health impacts, epidemiology, and evolution of CPV and FPV in wild carnivore populations remain largely obscure, and little is known about transmissions between wild and domestic carnivore populations, but such events undoubtedly occur in both directions. Since parvovirus infections can severely impact threatened or endangered wild carnivore populations, and foxes or other hosts likely played a role in the emergence of CPV, a better understanding of the epidemiology and evolution in hosts other than domestic cats and dogs appears crucial. The emergence of genetic variants of CPV that have different receptor binding and antigenic properties makes it difficult to determine which property if any is under selection, but raises concerns that vaccines will need to be updated to maintain the highest levels of protection.

The evolution of MEV in mink and of FPV and CPV in cats are less well understood that that of CPV in dogs, and many determinants of host specificity, adaptations, and pathogenicity are likely still unknown. The emergence of CPV represents a rare and important model of disease emergence through cross-species transmission, both because of high-quality data is available about the newly emerged virus and also because of the information that we have about the ancestral virus. A better understanding of the evolutionary dynamics of the ancestral virus before and after CPV emerged would also provide valuable information about the general principals of viral emergence in new hosts. Our understanding of the emergence and evolution of CPV has increased greatly over the last 30 years, but many details of the origins and evolution of the virus remain to be revealed.

Acknowledgements. Research supported by the US National Institutes of Health. K. Hoelzer was supported by Morris Animal Foundation Fellowship Training Grant D08FE-403.

\section{REFERENCES}

[1] Alexandersen S., Bloom M.E., Wolfinbarger J., Evidence of restricted viral replication in adult mink infected with Aleutian disease of mink parvovirus, J. Virol. (1988) 62:1495-1507.

[2] Appel M.J.G., Cooper B.J., Greisen H., Carmichael L.E., Status report: canine viral enteritis, J. Am. Vet. Med. Assoc. (1978) 173:1516-1518.

[3] Appel M.J.G., Scott F.W., Carmichael L.E., Isolation and immunisation studies of a canine parvo-like virus from dogs with haemorrhagic enteritis, Vet. Rec. (1979) 105:156-159.

[4] Barker I.K., Povey R.C., Voigt D.R., Response of mink, skunk, red fox and raccoon to inoculation with mink virus enteritis, feline panleukopenia and canine parvovirus and prevalence of antibody in wild carnivores in Ontario, Can. J. Comp. Med. (1983) 47: 188-197.

[5] Barker I.K., Parrish C.R., Parvovirus infections, in: Williams E., Barker I. (Eds.), Infectious diseases of wild mammals, Blackwell Publishing, 2001. 
[6] Battilani M., Scagliarini A., Ciulli S., Morganti L., Prosperi S., High genetic diversity of the VP2 gene of a canine parvovirus strain detected in a domestic cat, Virology (2006) 352:22-26.

[7] Biek R., Zarnke R.L., Gillin C., Wild M., Squires J.R., Poss M., Serologic survey for viral and bacterial infections in western populations of Canada lynx (Lynx canadensis), J. Wildl. Dis. (2002) 38:840-845.

[8] Biek R., Ruth T.K., Murphy K.M., Anderson C.R. Jr, Johnson M., DeSimone R., et al., Factors associated with pathogen seroprevalence and infection in Rocky Mountain cougars, J. Wildl. Dis. (2006) 42:606-615.

[9] Burger D., Gorham J.R., Ott R.L., Protection of cats against feline panleukopenia following mink virus enteritis vaccination, Small Anim. Clin. (1963) 3:611-614.

[10] Burger D., Gorham J.R., Mink virus enteritis, in: Davis W.R., Harstad L.H., Trainer D.O. (Eds.), Infectious diseases of wild mamals, Iowa University Press, Ames, Iowa, 1970, pp. 76-84.

[11] Chinchkar S.R., Mohana Subramanian B., Hanumantha Rao N., Rangarajan P.N., Thiagarajan D., Srinivasan V.A., Analysis of VP2 gene sequences of canine parvovirus isolates in India, Arch. Virol. (2006) 151:1881-1887.

[12] Costa A.P., Leite J.P., Labarthe N.V., Garcia R.C., Genomic typing of canine parvovirus circulating in the state of rio de janeiro, Brazil from 1995 to 2001 using polymerase chain reaction assay, Vet. Res. Commun. (2005) 29:735-743.

[13] Cotmore S.F., Tattersall P., The autonomously replicating parvoviruses of vertebrates, Adv. Virus Res. (1987) 33:91-174.

[14] Cotmore S.F., Tattersall P., DNA replication in the autonomous parvoviruses, Seminars in Virology (1995) 6:271-281.

[15] Decaro N., Martella V., Desario C., Bellacicco A.L., Camero M., Manna L., et al., First detection of canine parvovirus type $2 \mathrm{c}$ in pups with haemorrhagic enteritis in Spain, J. Vet. Med. B Infect. Dis. Vet. Public Health (2006) 53:468-472.

[16] Decaro N., Desario C., Elia G., Campolo M., Lorusso A., Mari V., et al., Occurrence of severe gastroenteritis in pups after canine parvovirus vaccine administration: a clinical and laboratory diagnostic dilemma, Vaccine (2007) 25:1161-1166.

[17] Decaro N., Desario C., Parisi A., Martella V., Lorusso A., Miccolupo A., et al., Genetic analysis of canine parvovirus type 2c, Virology (2009) 385:5-10.

[18] Doki M., Fujita K., Miura R., Yoneda M., Ishikawa Y., Taneno A., Kai C., Sequence analysis of
VP2 gene of canine parvovirus isolated from domestic dogs in Japan in 1999 and 2000, Comp. Immunol. Microbiol. Infect. Dis. (2006) 29:199-206.

[19] Driciru M., Siefert L., Prager K.C., Dubovi E., Sande R., Princee F., et al., A serosurvey of viral infections in lions (Panthera leo), from Queen Elizabeth National Park, Uganda, J. Wildl. Dis. (2006) 42:667-671.

[20] Gamoh K., Shimazaki Y., Makie H., Senda M., Itoh O., Inoue Y., The pathogenicity of canine parvovirus type-2b, FP84 strain isolated from a domestic cat, in domestic cats, J. Vet. Med. Sci. (2003) 65:1027-1029

[21] Gese E., Schultz R.D., Rongstad O.J., Andersen D.E., Prevalence of antibodies against canine parvovirus and canine distemper virus in wild coyotes in southeastern Colorado, J. Wildl. Dis. (1991) 27: 320-323.

[22] Hafenstein S., Bowman V.D., Sun T., Nelson C.D., Palermo L.M., Chipman P.R., et al., Structural comparison of different antibodies interacting with parvovirus capsids, J. Virol. (2009) 83:5556-5566.

[23] Hirayama K., Kano R., Hosokawa-Kanai T., Tuchiya K., Tsuyama S., Nakamura Y., et al., VP2 gene of a canine parvovirus isolate from stool of a puppy, J. Vet. Med. Sci. (2005) 67:139-143.

[24] Hoelzer K., Shackelton L.A., Holmes E.C., Parrish C.R., Within-host genetic diversity of endemic and emerging parvoviruses of dogs and cats, J. Virol. (2008) 82:11096-11105.

[25] Hoelzer K., Shackelton L.A., Parrish C.R., Presence and role of cytosine methylation in DNA viruses of animals, Nucleic Acids Res. (2008) 36:2825-2837.

[26] Hoelzer K., Shackelton L.A., Parrish C.R., Holmes E.C., Phylogenetic analysis reveals the emergence, evolution and dispersal of carnivore parvoviruses, J. Gen. Virol. (2008) 89:2280-2289.

[27] Hong C., Decaro N., Desario C., Tanner P., Pardo M.C., Sanchez S., et al., Occurrence of canine parvovirus type $2 \mathrm{c}$ in the United States, J. Vet. Diagn. Invest. (2007) 19:535-539.

[28] Horiuchi M., Yamaguchi Y., Gojobori T., Mochizuki M., Nagasawa H., Toyoda Y., et al., Differences in the evolutionary pattern of feline panleukopenia virus and canine parvovirus, Virology (1998) 249:440-452.

[29] Hueffer K., Govindasamy L., AgbandjeMcKenna M., Parrish C.R., Combinations of two capsid regions controlling canine host range determine canine transferrin receptor binding by canine and feline parvoviruses, J. Virol. (2003) 77:10099-10105. 
[30] Hueffer K., Parker J.S., Weichert W.S., Geisel R.E., Sgro J.Y., Parrish C.R., The natural host range shift and subsequent evolution of canine parvovirus resulted from virus-specific binding to the canine transferrin receptor, J. Virol. (2003) 77:1718-1726.

[31] Hueffer K., Parrish C.R., Parvovirus host range, cell tropism and evolution, Curr. Opin. Microbiol. (2003) 6:392-398.

[32] Ikeda Y., Miyazawa T., Nakamura K., Naito R., Inoshima Y., Tung K.C., et al., Serosurvey for selected virus infections of wild carnivores in Taiwan and Vietnam, J. Wildl. Dis. (1999) 35:578-581.

[33] Ikeda Y., Mochizuki M., Naito R., Nakamura K., Miyazawa T., Mikami T., Takahashi E., Predominance of canine parvovirus (CPV) in unvaccinated cat populations and emergence of new antigenic types of CPVs in cats, Virology (2000) 278:13-19.

[34] Ikeda Y., Nakamura K., Miyazawa T., Takahashi E., Mochizuki M., Feline host range of canine parvovirus: recent emergence of new antigenic types in cats, Emerg. Infect. Dis. (2002) 8:341-346.

[35] Kang B.K., Song D.S., Lee C.S., Jung K.I., Park S.J., Kim E.M., Park B.K., Prevalence and genetic characterization of canine parvoviruses in Korea, Virus Genes (2008) 36:127-133.

[36] Kapil S., Cooper E., Lamm C., Murray B., Rezabek G., Johnston L. III, et al., Canine parvovirus types $2 \mathrm{c}$ and $2 \mathrm{~b}$ circulating in North American dogs in 2006 and 2007, J. Clin. Microbiol. (2007) 45:40444047.

[37] Kapil S., Rezabek G., Germany B., Johnston L., Isolation of a virus related to canine parvovirus type 2 from a raccoon (Procyon lotor), Vet. Rec. (2010) 166:24-25.

[38] Larson L.J., Schultz R.D., Do two current canine parvovirus type 2 and $2 \mathrm{~b}$ vaccines provide protection against the new type 2c variant?, Vet. Ther. (2008) 9:94-101.

[39] Llamas-Saiz A.L., Agbandje-McKenna M., Parker J.S.L., Wahid A.T.M., Parrish C.R., Rossmann M.G., Structural analysis of a mutation in canine parvovirus which controls antigenicity and host range, Virology (1996) 225:65-71.

[40] Martella V., Decaro N., Elia G., Buonavoglia C., Surveillance activity for canine parvovirus in Italy, J. Vet. Med. B Infect. Dis. Vet. Public Health (2005) 52:312-315.

[41] Mochizuki M., Harasawa R., Nakatani H., Antigenic and genomic variabilities among recently prevalent parvoviruses of canine and feline origin in Japan, Vet. Microbiol. (1993) 38:1-10.
[42] Murphy F.A., Fauquet C.M., Mayo M.A., Jarvis S.A., Ghabrial S.A., Summers M.D., et al., International Committee on Taxonomy of Viruses, International Union of Microbiological Societies. Virology Division Virus taxonomy/G: classification and nomenclature of viruses: Sixth report of the International Committee on Taxonomy of Viruses, Arch. Virol. (1995) (Suppl.) 586 p.

[43] Myers W.L., Alberts J.O., Brandley C.A., Certain characteristics of the virus of infectious enteritis of mink and observations on pathogenesis of the disease - preliminary report, Can. J. Comp. Med. (1959) 23:282-287.

[44] Nakamura K., Sakamoto M., Ikeda Y., Sato E., Kawakami K., Miyazawa T., et al., Pathogenic potential of canine parvovirus types $2 \mathrm{a}$ and $2 \mathrm{c}$ in domestic cats, Clin. Diagn. Lab. Immunol. (2001) 8:663-668.

[45] Nakamura M., Tohya Y., Miyazawa T., Mochizuki M., Phung H.T., Nguyen N.H., et al., A novel antigenic variant of canine parvovirus from a Vietnamese dog, Arch. Virol. (2004) 149:2261-2269.

[46] Nelson C.D., Minkkinen E., Bergkvist M., Hoelzer K., Fisher M., Bothner B., Parrish C.R., Detecting small changes and additional peptides in the canine parvovirus capsid structure, J. Virol. (2008) 82:10397-10407.

[47] Op De Beeck A., Caillet-Fauquet P., Viruses and the cell cycle, Prog. Cell Cycle Res. (1997) 3:1-19.

[48] Palermo L.M., Hafenstein S.L., Parrish C.R., Purified feline and canine transferrin receptors reveal complex interactions with the capsids of canine and feline parvoviruses that correspond to their host ranges, J. Virol. (2006) 80:8482-8492.

[49] Parrish C.R., Gorham J.R., Schwartz T.M., Carmichael L.E., Characterisation of antigenic variation among mink enteritis virus isolates, Am. J. Vet. Res. (1984) 45:2591-2599.

[50] Parrish C.R., Carmichael L.E., Characterization and recombination mapping of an antigenic and hostrange mutation of canine parvovirus, Virology (1986) 148:121-132.

[51] Parrish C.R., Leathers C.W., Pearson R., Gorham J.R., Comparisons of feline panleukopenia virus, canine parvovirus, racoon parvovirus, and mink enteritis virus and their pathogenicity for mink and ferrets, Am. J. Vet. Res. (1987) 48:1429-1435.

[52] Parrish C.R., Aquadro C., Strassheim M.L., Evermann J.F., Sgro J.-Y., Mohammed H., Rapid antigenic-type replacement and DNA sequence evolution of canine parvovirus, J. Virol. (1991) 65:6544-6552. 
[53] Parrish C.R., The emergence and evolution of canine parvovirus - an example of recent host range mutation, Semin. Virol. (1994) 5:121-132.

[54] Parrish C.R., Pathogenesis of feline panleukopenia virus and canine parvovirus, Baillieres Clin. Haematol. (1995) 8:57-71.

[55] Parrish C.R., Host range relationships and the evolution of canine parvovirus, Vet. Microbiol. (1999) 69:29-40.

[56] Parrish C.R., Truyen U., The evolution of parvoviruses, in: Domingo E., Webster R.G., Holland J.J., Picknett T. (Eds.), Origin and evolution of viruses, Academic Press, London, 1999, pp. 421-439.

[57] Pereira C.A., Leal E.S., Durigon E.L., Selective regimen shift and demographic growth increase associated with the emergence of high-fitness variants of canine parvovirus, Infect. Genet. Evol. (2007) 7: 399-409.

[58] Perez R., Francia L., Romero V., Maya L., Lopez I., Hernandez M., First detection of canine parvovirus type 2c in South America, Vet. Microbiol. (2007) 124:147-152.

[59] Porter D.D., Aleutian disease: a persistent parvovirus infection of mink with a maximal but ineffective host humoral immune response, Prog. Med. Virol. (1986) 33:42-60.

[60] Qin Q., Loeffler I.K., Li M., Tian K., Wei F., Sequence analysis of a canine parvovirus isolated from a red panda (Ailurus fulgens) in China, Virus Genes (2007) 34:299-302.

[61] Qin Q., Wei F., Li M., Dubovi E.J., Loeffler I.K., Serosurvey of infectious disease agents of carnivores in captive red pandas (Ailurus fulgens) in China, J. Zoo Wildl. Med. (2007) 38:42-50.

[62] Ramsauer S., Bay G., Meli M., HofmannLehmann R., Lutz H., Seroprevalence of selected infectious agents in a free-ranging, low-density lion population in the Central Kalahari Game Reserves in Botswana, Clin. Vaccine Immunol. (2007) 14:808-810.

[63] Schofield F.W., Virus enteritis in mink, N. Am. Vet. (1949) 30:651-654.

[64] Shackelton L.A., Parrish C.R., Truyen U., Holmes E.C., High rate of viral evolution associated with the emergence of carnivore parvovirus, Proc. Natl. Acad. Sci. USA (2005) 102:379-384.

[65] Steinel A., Munson L., van Vuuren M., Truyen U., Genetic characterization of feline parvovirus sequences from various carnivores, J. Gen. Virol. (2000) 81: $345-350$.
[66] Steinel A., Parrish C.R., Bloom M.E., Truyen U., Parvovirus infections in wild carnivores, J. Wildl. Dis. (2001) 37:594-607.

[67] Thomas N.J., Foreyt W.J., Evermann J.F., Windberg L.A., Knowlton F.F., Seroprevalence of canine parvovirus in wild coyotes from Texas, Utah, and Idaho (1972 to 1983), J. Am. Vet. Med. Assoc. (1984) 185:1283-1287.

[68] Truyen U., Parrish C.R., Canine and feline host ranges of canine parvovirus and feline panleukopenia virus: distinct host cell tropisms of each virus in vitro and in vivo, J. Virol. (1992) 66:5399-5408.

[69] Truyen U., Platzer G., Parrish C.R., Hanichen T., Hermanns W., Kaaden O.R., Detection of canine parvovirus DNA in paraffin-embedded tissues by polymerase chain reaction, Zentralbl. Veterinarmed. B (1994) 41:148-152.

[70] Truyen U., Gruenberg A., Chang S.F., Obermaier B., Veijalainen P., Parrish C.R., Evolution of the feline-subgroup parvoviruses and the control of canine host range in vivo, J. Virol. (1995) 69:4702-4710.

[71] Truyen U., Evermann J.F., Vieler E., Parrish C.R., Evolution of canine parvovirus involved loss and gain of feline host range, Virology (1996) 215:186189.

[72] Truyen U., Platzer G., Parrish C.R., Antigenic type distribution among canine parvoviruses in dogs and cats in Germany, Vet. Rec. (1996) 138:365-366.

[73] Truyen U., Muller T., Heidrich R., Tackmann K., Carmichael L.E., Survey on viral pathogens in wild red foxes (Vulpes vulpes) in Germany with emphasis on parvoviruses and analysis of a DNA sequence from a red fox parvovirus, Epidemiol. Infect. (1998) 121:433-440.

[74] Veijalainen P., Characterization of biological and antigenic properties of raccoon $\mathrm{dog}$ and blue fox parvoviruses: a monoclonal antibody study, Vet. Microbiol. (1988) 16:219-230.

[75] Wills C.G., Notes on infectious enteritis of mink and its relationship to feline enteritis, Can. J. Comp. Med. (1952) 16:419-420.

[76] Wills G., Belcher J., The prevention of virus enteritis of mink with commercial feline panleukopenia vaccine, J. Am. Vet. Med. Assoc. (1956) 128:559560 .

[77] Zarnke R.L., Ver Hoef J.M., Delong R.A., Serologic survey for selected disease agents in wolves (canis lupus) from Alaska and the Yukon territory, 1984-2000, J. Wildl. Dis. (2004) 40:632-638. 